\title{
Theoretical Studies of Structure, Spectroscopy, and Properties of a New Hydrazine Derivative
}

\author{
Hajar Sahebalzamani, Farshid Salimi, and Elmira Dornapour \\ Department of Chemistry, Faculty of Science, Ardabil Branch, Islamic Azad University, Ardabil, Iran \\ Correspondence should be addressed to Hajar Sahebalzamani; sahebalzamanih@yahoo.com
}

Received 26 June 2012; Revised 25 August 2012; Accepted 26 August 2012

Academic Editor: Liviu Mitu

Copyright (C) 2013 Hajar Sahebalzamani et al. This is an open access article distributed under the Creative Commons Attribution License, which permits unrestricted use, distribution, and reproduction in any medium, provided the original work is properly cited.

We will report a combined experimental and theoretical study on molecular structure, vibrational spectra, and energies of (E)1-(2,4-dinitrophenyl)-2-[(4-methylphenyl)methylidene]hydrazine (1). The molecular geometry and vibrational frequencies and energies in the ground state are calculated by using HF and DFT levels of theory with 6-311G basis sets. The calculated HOMO and LUMO energies also confirm that charge transfer occurs within the molecule. The harmonic vibrational frequencies were calculated, and the scaled values have been compared with experimental FTIR and FT-Raman spectra. The observed and the calculated frequencies are found to be in good agreement. The experimental spectra also coincide satisfactorily with those of theoretically constructed bar-type spectrograms.

\section{Introduction}

The properties of hydrazides and hydrazones are of interest due to their biological activities and their use as metal extracting agencies [1]. The hydrazones derivatives are used as fungicides and in the treatment of diseases such as tuberculosis, leprosy, and mental disorders. The complexes of various hydrazones are reported to act as inhibitors of enzymes [2]. Many substituted hydrazides are employed in the treatment of psychotic and psychoneurotic conditions. Carboxylic acid hydrazides are known to exhibit strong antibacterial activities which are enhanced by complexation with metal ions. Chemistry of Schiff bases has been intensively investigated in recent years, owing to their coordination properties and diverse applications. Schiff base hydrazones are widely used in analytical chemistry as a selective metal extracting agent as well as in spectroscopic determination of certain transition metals [3-6]. Schiff bases play an important role in inorganic chemistry as they easily form stable complexes with most transition metal ions in the periodic table. The development of the field of bioinorganic chemistry has increased the interest in Schiff base complexes, since it has been recognized that many of these complexes may serve as models for biologically important species [7-11]. Schiff base metal complexes have been widely studied because they have industrial, fungicide, antibacterial, anticancer, and herbicidal applications $[12,13]$.

However, the detailed ab initio and DFT (LSDA) with 6-311G comparative studies on the complete FTIR spectra of compound (1) have not been reported so far. In this study, molecular geometry, optimized parameters, and vibrational frequencies are computed and the performance of the computational methods for the ab initio and DFT (LSDA) levels with the 6-311G basis sets is compared. The HOMO represents the ability to donate an electron, LUMO as an electron acceptor represents the ability to obtain an electron. The HOMO and LUMO energy calculated by the ab initio and DFT (LSDA) levels with the 6-311G basis sets.

\section{Experimental}

2.1. Computational Details. All calculations were performed using the Gaussian 03 program on a Windows-XP operating PC. The molecular structure of the title compound in the ground state is computed by performing the ab initio and DFT (LSDA) with the 6-311G basis sets. 


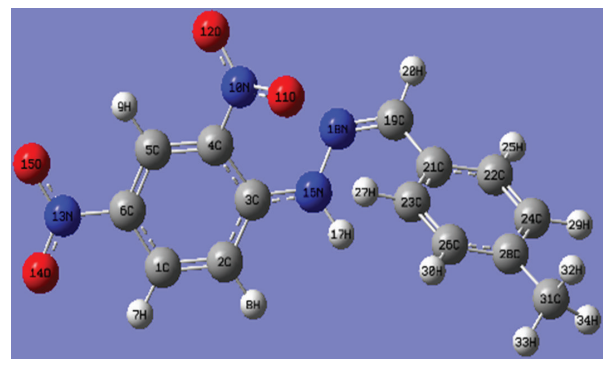

FIgURE 1: Molecular structure and atom numbering scheme adopted in this study for (1).

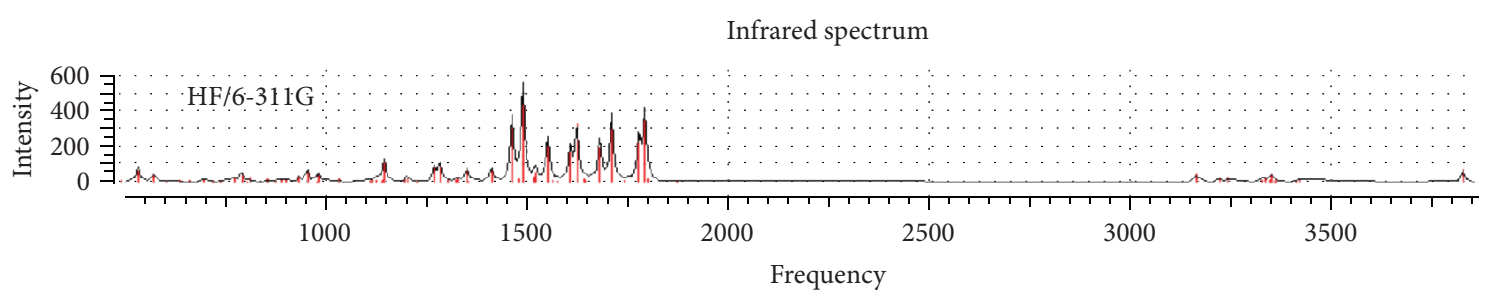

(a)

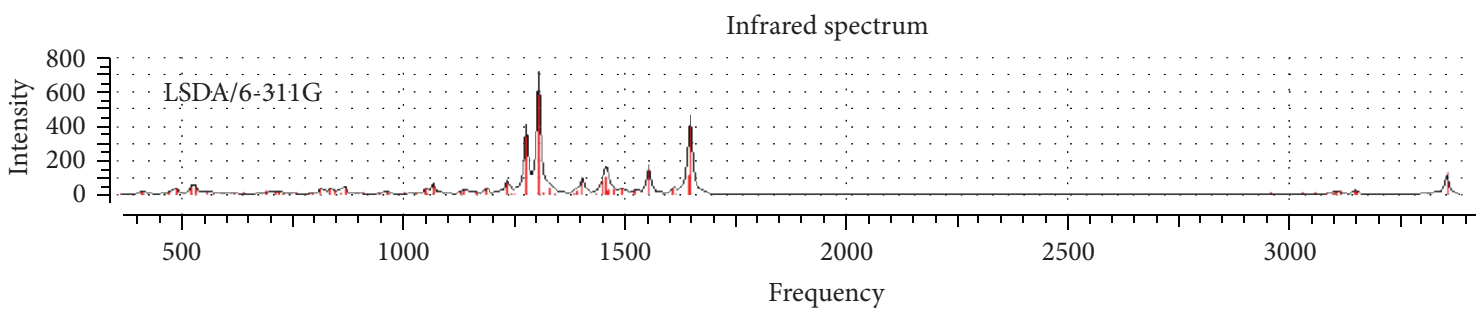

(b)

FIGURE 2: Calculated infrared spectra of compound (1).

\section{Results and Discussion}

3.1. Molecular Geometry. The molecular structure of compound (1) belongs to C1 point group symmetry. The optimized molecular structure of title molecule is obtained from Gaussian 03W and Gaussview programs are shown in Figure 1. The optimized structural parameters of compound (1) calculated by the ab initio and DFT (LSDA) levels with the 6-311G basis sets are listed in Table 1.

3.2. Vibrational Analysis. Vibrational spectroscopy was extensively used in organic chemistry for the identification of functional groups of organic compounds, the study of molecular conformations, reaction kinetics, and so forth. The observed and calculated data of the vibrational spectrum of compound (1) are given in Table 2. The suggested reason was that the result obtained by the calculation was harmonic oscillation frequency, while the experimental value contained the anharmonic oscillation frequency. Assignment of compound systems could be proposed on the basis of frequency agreement between the computed harmonics and the observed fundamental modes. The calculated infrared spectra for different methods of compound (1) are presented in Figure 2. Correlation graphs between the scaled calculated and observed results for the assigned fundamentals in the region $4000-500 \mathrm{~cm}^{-1}$ are shown in Figure 3.

Comparing the observed and calculated frequencies shows that the results of our computations are in good agreement with the experiment.

In the spectrum of ligand, the strong IR absorption at $3447 \mathrm{~cm}^{-1}$ is due to $\mathrm{N}-\mathrm{H}$ frequency. The calculated stretching vibration modes of the $\mathrm{N}-\mathrm{H}$ band for compound (1) with $\mathrm{ab}$ initio and DFT (LSDA) levels with the 6-311G basis sets are 3814 and $3353 \mathrm{~cm}^{-1}$ (unscaled), respectively. Obviously, LSDA functional gives results in closest agreement with the observed frequencies over the other methods surveyed. The experimental $\mathrm{C}=\mathrm{N}$ bands were observed at $1591 \mathrm{~cm}^{-1}$ as sharp bands. The calculated stretching vibration mode of the $\mathrm{C}=\mathrm{N}$ band for compound (1) with HF and LSDA methods at 6-311G basis set was somewhat shifted to the higher frequency appearing at 1792 and $1608 \mathrm{~cm}^{-1}$, respectively.

The FT-IR spectrum showed absorption bands at $1092 \mathrm{~cm}^{-1}$ which were assigned to N-N and calculated theoretically by HF/LSDA at 1145 and $1066 \mathrm{~cm}^{-1}$ for compound (1).

As can be seen from Figure 3, experimental fundamentals have a good correlation with LSDA/6-311G. 
TABLE 1: Optimized geometrical parameters for compound (1) at (HF/LSDA) methods by using 6-311G basis set.

\begin{tabular}{|c|c|c|}
\hline \multirow{2}{*}{ Geometrical parameters } & \multicolumn{2}{|c|}{$6-311 G$} \\
\hline & $\mathrm{HF}$ & LSDA \\
\hline \multicolumn{3}{|l|}{ Bond length $(\AA)$} \\
\hline $\mathrm{C} 1-\mathrm{C} 2$ & 1.371 & 1.374 \\
\hline $\mathrm{C} 2-\mathrm{C} 3$ & 1.404 & 1.407 \\
\hline $\mathrm{C} 3-\mathrm{C} 4$ & 1.399 & 1.411 \\
\hline $\mathrm{C} 4-\mathrm{C} 5$ & 1.379 & 1.382 \\
\hline C5-C6 & 1.376 & 1.380 \\
\hline C6-C1 & 1.389 & 1.396 \\
\hline N13-C6 & 1.436 & 1.434 \\
\hline $\mathrm{N} 13-\mathrm{O} 14$ & 1.229 & 1.265 \\
\hline $\mathrm{N} 13-\mathrm{O} 15$ & 1.227 & 1.263 \\
\hline N10-C4 & 1.447 & 1.438 \\
\hline N10-O11 & 1.224 & 1.267 \\
\hline $\mathrm{N} 10-\mathrm{O} 12$ & 1.226 & 1.259 \\
\hline $\mathrm{C} 3-\mathrm{N} 16$ & 1.365 & 1.356 \\
\hline N16-N18 & 1.374 & 1.365 \\
\hline N18-C19 & 1.267 & 1.298 \\
\hline $\mathrm{C} 19-\mathrm{C} 21$ & 1.479 & 1.450 \\
\hline $\mathrm{C} 21-\mathrm{C} 22$ & 1.392 & 1.398 \\
\hline $\mathrm{C} 21-\mathrm{C} 23$ & 1.393 & 1.404 \\
\hline $\mathrm{C} 22-\mathrm{C} 24$ & 1.383 & 1.385 \\
\hline $\mathrm{C} 26-\mathrm{C} 23$ & 1.385 & 1.384 \\
\hline $\mathrm{C} 28-\mathrm{C} 26$ & 1.392 & 1.398 \\
\hline $\mathrm{C} 24-\mathrm{C} 28$ & 1.392 & 1.397 \\
\hline C28-N31 & 1.507 & 1.488 \\
\hline \multicolumn{3}{|l|}{ Bond angle $\left({ }^{\circ}\right)$} \\
\hline $\mathrm{C} 1-\mathrm{C} 2-\mathrm{C} 3$ & 121.4 & 120.6 \\
\hline $\mathrm{C} 2-\mathrm{C} 3-\mathrm{C} 4$ & 117.2 & 118.2 \\
\hline $\mathrm{C} 3-\mathrm{C} 4-\mathrm{C} 5$ & 121.7 & 121.0 \\
\hline $\mathrm{C} 4-\mathrm{C} 5-\mathrm{C} 6$ & 119.1 & 118.8 \\
\hline C5-C6-C1 & 120.9 & 121.5 \\
\hline C1-C6-N13 & 119.6 & 119.2 \\
\hline C5-C6-N13 & 119.4 & 119.1 \\
\hline O14-N13-O15 & 123.5 & 124.2 \\
\hline C3-C4-N10 & 122.3 & 121.5 \\
\hline C5-C4-N10 & 115.7 & 116.9 \\
\hline C4-N10-O11 & 118.1 & 117.8 \\
\hline $\mathrm{C} 4-\mathrm{N} 10-\mathrm{O} 12$ & 117.7 & 117.7 \\
\hline $11-\mathrm{N} 10-\mathrm{O} 12$ & 124.0 & 124.1 \\
\hline C2-C3-N16 & 118.8 & 120.4 \\
\hline C4-C3-N16 & 123.8 & 121.3 \\
\hline C3-N16-N18 & 119.0 & 120.1 \\
\hline N16-N18-C19 & 120.7 & 118.0 \\
\hline N18-C19-C21 & 128.4 & 126.5 \\
\hline C19-C21-C22 & 119.5 & 121.1 \\
\hline C19-C21-C23 & 121.9 & 119.8 \\
\hline C21-C22-C24 & 120.7 & 120.4 \\
\hline C22-C24-C28 & 121.0 & 121.1 \\
\hline $\mathrm{C} 24-\mathrm{C} 28-\mathrm{C} 26$ & 118.0 & 118.2 \\
\hline C28-C26-C23 & 121.2 & 121.2 \\
\hline C26-C23-C21 & 120.5 & 120.1 \\
\hline C24-C28-C31 & 120.9 & 120.9 \\
\hline C26-C28-C31 & 120.9 & 120.8 \\
\hline
\end{tabular}

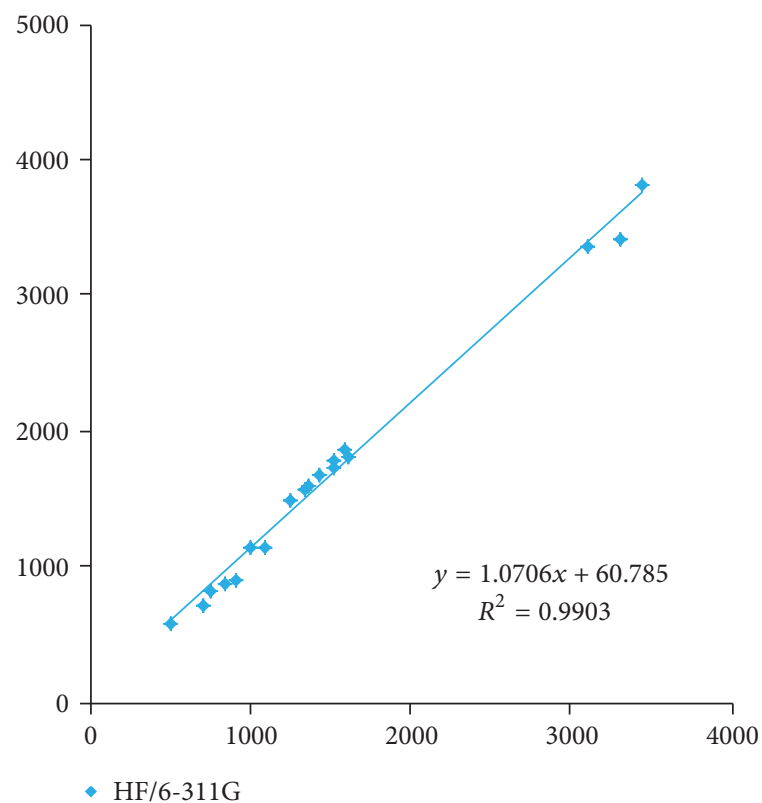

(a)

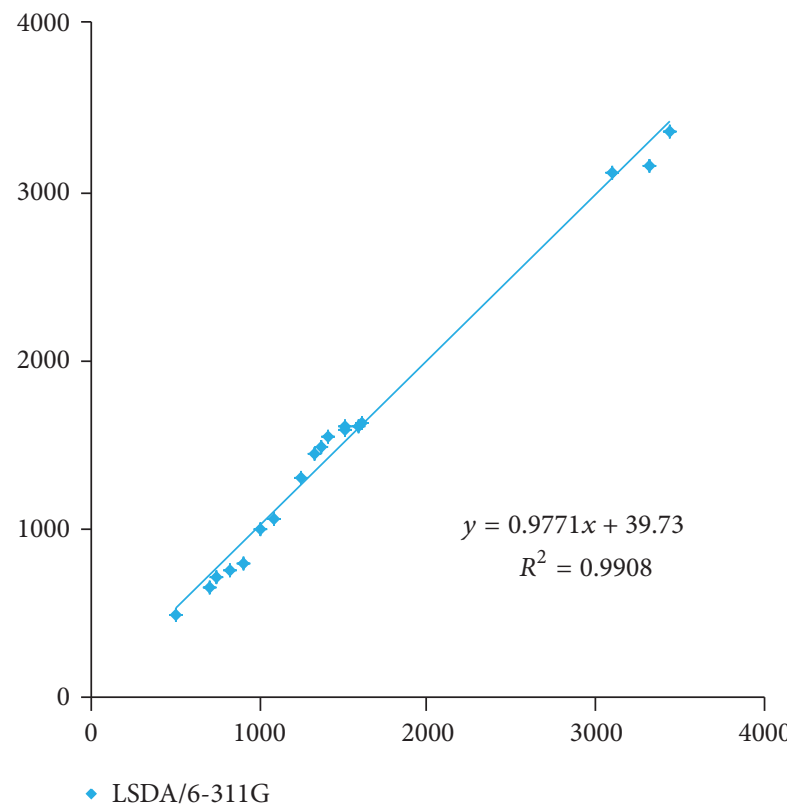

(b)

FIGURE 3: Scaled calculated vibrational frequencies in comparison to the experimental obtained data and correlation coefficients for compound (1).

As a result, the fundamental vibrational are in good consistency with the experimental results and are found a good agreement above the predicated literature.

3.3. Orbital Analysis. The UV-Vis spectral analysis of compound (1) has been calculated by TD-HF/6-311G and TDLSDA/6-311G methods along with measured UV-Vis data which are summarized in Table 3. The UV-Vis spectrum of compound (1) is shown in Figure 4 as measured in 
TABLE 2: Observed and HF/DFT (LSDA) with 6-311G level calculated vibrational frequencies of compound (1).

\begin{tabular}{|c|c|c|c|c|c|}
\hline Experimental & $\underset{6-311 G}{H F}$ & Int. (IR) & $\begin{array}{c}\text { LSDA } \\
6-311 G\end{array}$ & Int. (IR) & Vibrational assignments \\
\hline 3447 & 3814 & 66 & 3353 & 123 & $v \mathrm{NH}$ \\
\hline 3311 & 3410 & 2 & 3150 & 8 & $v \mathrm{~s} C H$ \\
\hline- & 3361 & 8 & 3115 & 1 & vasCH \\
\hline 3103 & 3356 & 3 & 3113 & 16 & $v \mathrm{sCH}$ \\
\hline- & 3345 & 11 & 3100 & 6 & $v \mathrm{CH}$ \\
\hline - & 3331 & 15 & 3080 & 1 & $v \operatorname{asCH}$ \\
\hline - & 3242 & 23 & 3058 & 7 & vas $\mathrm{CH}_{3}$ \\
\hline- & 3161 & 39 & 2954 & 13 & $v \mathrm{sCH}_{3}$ \\
\hline 1615 & 1799 & 20 & 1642 & 113 & $v \mathrm{~s} C-\mathrm{C}+\beta \mathrm{CH}$ \\
\hline 1591 & 1873 & 9 & 1615 & 4 & $v \mathrm{~s} C-\mathrm{C}+\beta \mathrm{CH}+\nu \mathrm{sC}-\mathrm{N}$ \\
\hline 1511 & 1792 & 382 & 1608 & 38 & $v \mathrm{sC}-\mathrm{N}+\beta \mathrm{CH}+\beta \mathrm{NH}$ \\
\hline 1509 & 1741 & 7 & 1585 & 3 & $\nu \mathrm{C}-\mathrm{C}+\beta \mathrm{CH}+\beta \mathrm{NH}$ \\
\hline 1419 & 1681 & 54 & 1552 & 25 & $\beta \mathrm{CH}$ \\
\hline 1366 & 1607 & 196 & 1493 & 34 & $\beta \mathrm{NH}+\nu \operatorname{asNO}_{2}+\beta \mathrm{CH}$ \\
\hline 1331 & 1562 & 5 & 1450 & 76 & $v \operatorname{asNO}_{2}+\beta \mathrm{CH}$ \\
\hline 1257 & 1489 & 544 & 1305 & 690 & $\beta \mathrm{NH}+\nu \mathrm{sNO}_{2}+\beta \mathrm{CH}$ \\
\hline 1092 & 1145 & 121 & 1066 & 61 & $v \mathrm{~N}-\mathrm{N}+\beta \mathrm{CH}+\beta \mathrm{NH}$ \\
\hline 1008 & 1136 & 1 & 1001 & 13 & $\gamma \mathrm{CH}$ \\
\hline 908 & 890 & 16 & 795 & 8 & $\delta \mathrm{NO}_{2}$ \\
\hline 831 & 873 & 7 & 759 & 8 & $\gamma \mathrm{CN}+\gamma \mathrm{CH}$ \\
\hline 740 & 811 & 23 & 713 & 8 & $\omega \mathrm{NO}_{2}+\gamma \mathrm{CH}$ \\
\hline 705 & 720 & 1 & 655 & 4 & $\beta \mathrm{C}-\mathrm{C}-\mathrm{C}+\beta \mathrm{C}-\mathrm{NO}_{2}+\omega \mathrm{NO}_{2}$ \\
\hline 508 & 571 & 30 & 487 & 34 & $\gamma \mathrm{CH}+\gamma \mathrm{NH}$ \\
\hline
\end{tabular}

TABLE 3: Experimental and calculated absorption wavelength, energies, and oscillator strengths of compound (1) using the TD-HF/B3LYP/6$311 \mathrm{G}$ method.

\begin{tabular}{lccccc}
\hline \multicolumn{2}{c}{ Excitation energies } & \multicolumn{2}{c}{ Wavelength cal. gas phase } & \multicolumn{2}{c}{ Oscillator strength (f) } \\
HF/6-311G & LSDA/6-311G & HF/6-311G & LSDA/6-311G & HF/6-311G & LSDA/6-311G \\
\hline 4.345 & 2.350 & 285 & 527 & 0.0080 & 0.0224 \\
4.425 & 2.582 & 280 & 480 & 0.0005 & 0.4102 \\
4.755 & 2.863 & 260 & 432 & 0.0522 & - \\
4.847 & 2.901 & 255 & 427 & 0.0008 & 0.0003 \\
4.956 & 3.081 & 250 & 402 & 0.8317 & 0.0025 \\
5.529 & 3.119 & 224 & 397 & 0.0604 & 0.0002 \\
\hline
\end{tabular}

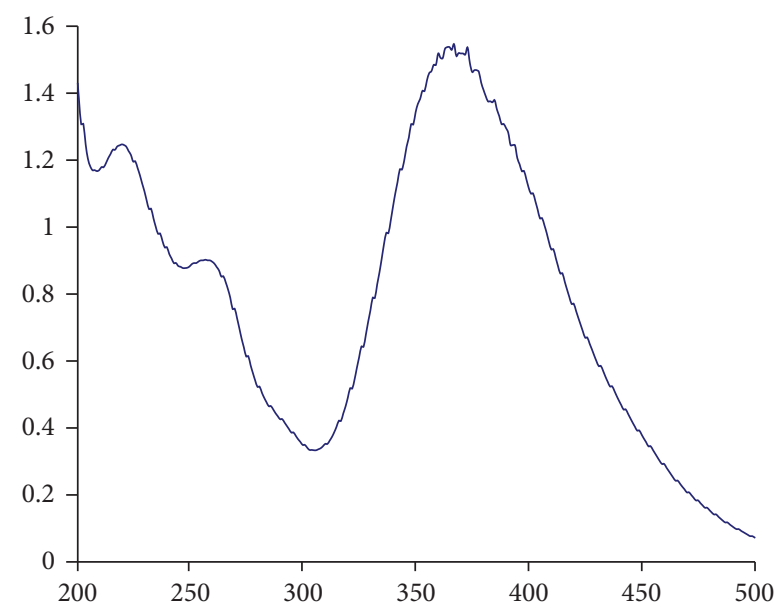

FIgURE 4: UV-Vis spectrum of (E)-1-(2,4-dinitrophenyl)-2-[(4methylphenyl)methylidene]hydrazine. acetonitrile solution. Both the highest occupied molecular orbital (HOMO) and lowest unoccupied molecular orbital (LUMO) are the main orbitals that take part in chemical stability. The HOMO represents the ability to donate an electron, LUMO as an electron acceptor represents the ability to obtain an electron. The HOMO and LUMO energy calculated by the ab initio and DFT (LSDA) levels with the 6-311G basis set Figure 5. This electronic absorption corresponds to the transition from the ground to the first excited state and is mainly described by one electron excitation from the highest occupied molecular or orbital (LUMO). The $\mathrm{HOMO}$ is located over the group, and the HOMO $\rightarrow$ LUMO transition implies an electron density transfer to ring from chlorine and partially from ring.

The HOMO energy calculated by LSDA/6-311G method is higher than by HF method. The biggest LUMO energy value is 0.10537 a.u. obtained using HF/6-311G. The biggest value of energy gap $(\Delta \mathrm{E})$ between $\mathrm{HOMO}$ and LUMO 


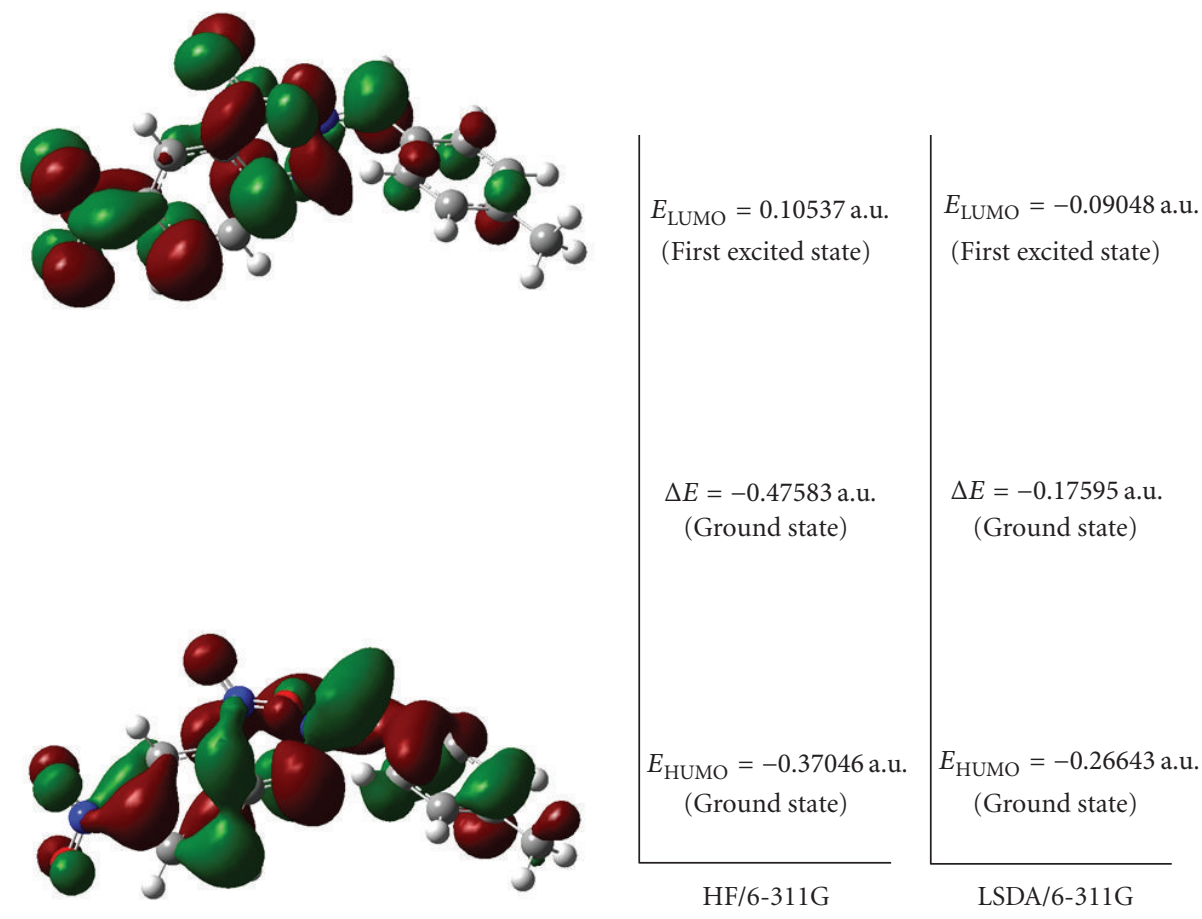

FIGURE 5: The atomic orbital compositions of the frontier molecular orbital for compound (1).

energies is -0.17595 a.u. obtained at LSDA/6-311G whereas the smallest one is -0.47583 a.u. obtained at $\mathrm{HF} / 6-311 \mathrm{G}$. The total energies are found to decrease with increase of basis set dimension.

\section{Acknowledgment}

The authors thank Islamic Azad University, Ardabil Branch, for financial support.

\section{References}

[1] T. L. Gilchrist, Heterocylic Chemistry, John Wiley \& Sons, New York, NY, USA, 1988.

[2] J. A. Fallas, L. González, and I. Corral, "Density functional theory rationalization of the substituent effects in trifluoromethylpyridinol derivatives," Tetrahedron, vol. 65, no. 1, pp. 232-239, 2009.

[3] W. F. Liaw, N. H. Lee, C. H. Chen, C. M. Lee, G. H. Lee, and S. M. Peng, "Dinuclear and mononuclear iron(II)-thiolate complexes with mixed $\mathrm{CO} / \mathrm{CN}$ - ligands: synthetic advances for iron sites of [Fe]-only hydrogenases," Journal of the American Chemical Society, vol. 122, no. 3, pp. 488-494, 2000.

[4] P. J. Trotter and P. A. White, "Resonance raman determination of the triiodide structure in bis(Tetrathiotetracene)triiodide organic conductor compared with the poly(Vinyl Alcohol)Iodine complex," Applied Spectroscopy, vol. 32, no. 3, p. 323, 1978.

[5] K. Y. Rajpure and C. H. Bhosale, " $\mathrm{Sb}_{2} \mathrm{~S}_{3}$ semiconductor-septum rechargeable storage cell," Materials Chemistry and Physics, vol. 64, no. 1, pp. 70-74, 2000.
[6] S. Licht, "Electrolyte modified photoelectrochemical solar cells," Solar Energy Materials and Solar Cells, vol. 38, no. 1-4, pp. 305-319, 1995.

[7] J. M. Altenburger, G. Y. Lassalle, M. Matrougui et al., "SSR182289A, a selective and potent orally active thrombin inhibitor," Bioorganic and Medicinal Chemistry, vol. 12, no. 7, pp. 1713-1730, 2004.

[8] H. Camp and J. Perk, Hand Book of American Chemical Society, 2000.

[9] M. Gallego, M. Garcia-Vargas, and M. Valcarcel, "Pyridine2-carbaldehyde 2-hydroxybenzoylhydrazone as a selective reagent for the extraction and spectrophotometric determination of iron(II)," The Analyst, vol. 104, no. 1239, pp. 613-619, 1979.

[10] M. Gallego, M. Garcia-Vargas, F. Pino, and M. Valcarcel, "Analytical applications of picolinealdehyde salicyloylhydrazone. Spectrophotometric determination of nickel and zinc," Microchemical Journal, vol. 23, no. 3, pp. 353-359, 1978.

[11] S. S. Patel and A. D. Sawant, "Pyridine-2-acetaldehyde salicyloylhydrazone as reagent for extractive and spectrophotometric determination of cobalt(II) at trace level," Indian Journal of Chemical Technology, vol. 8, no. 2, pp. 88-91, 2001.

[12] K. H. Reddy and K. B. Chandrasekhar, "Simultaneous first derivative spectrophotometric determination of nickel(II) and copper(II) in alloys with diacetylmonoxime benzoylhydrazone," Indian Journal of Chemistry A, vol. 40, no. 7, pp. 727-732, 2001.

[13] C. Jayabalakrishnan and K. Natarajan, "Synthesis, characterization, and biological activities of ruthenium(Ii) carbonyl complexes containing bifunctional tridentate schiff bases," Synthesis and Reactivity in Inorganic and Metal-Organic Chemistry, vol. 31, no. 6, pp. 983-995, 2001. 

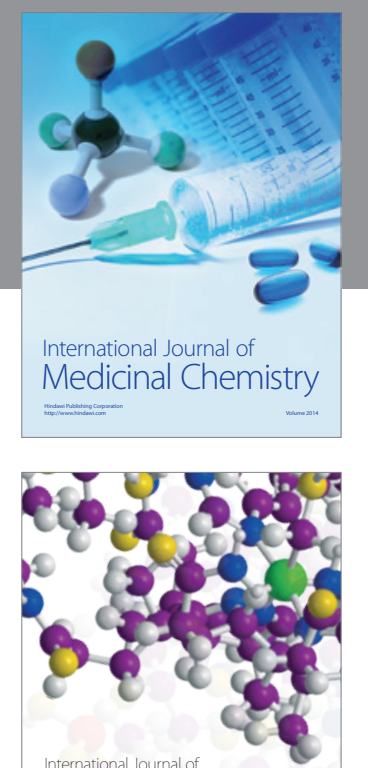

\section{Carbohydrate} Chemistry

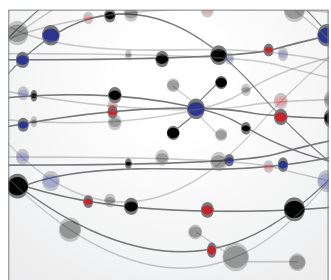

The Scientific World Journal
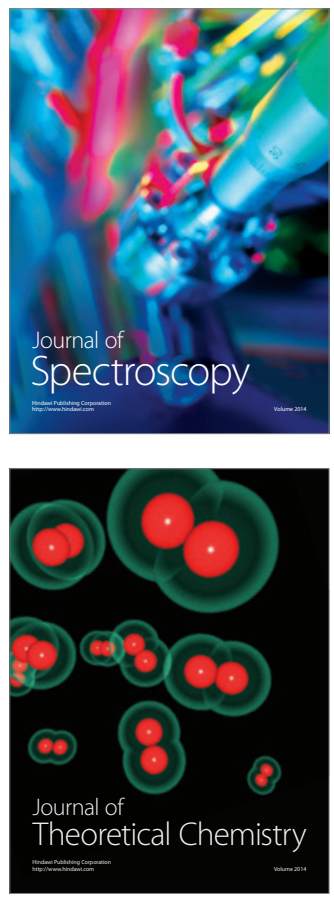
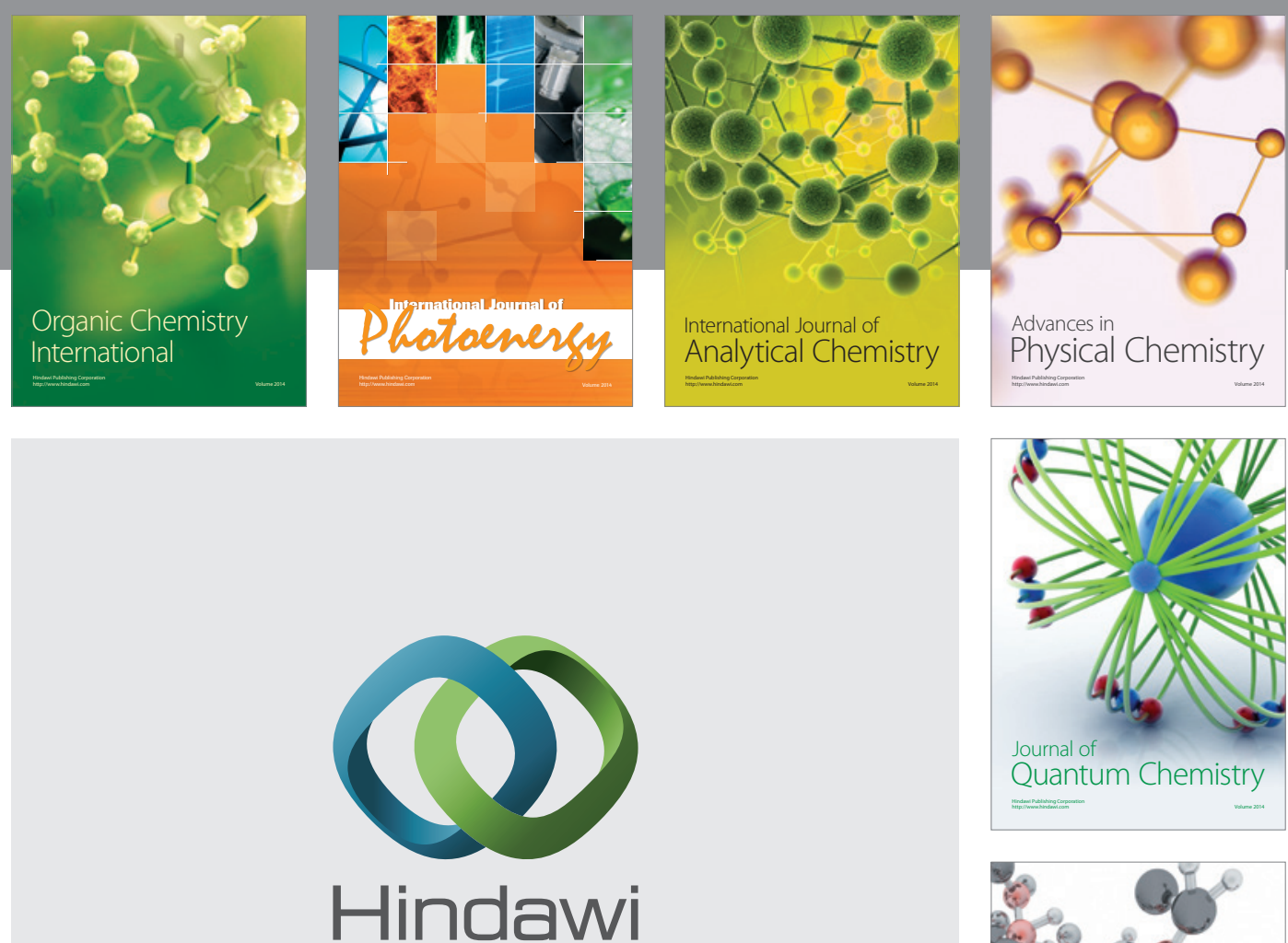

Submit your manuscripts at

http://www.hindawi.com

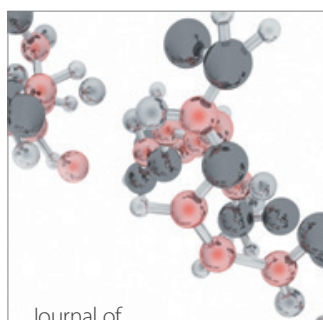

Analytical Methods

in Chemistry

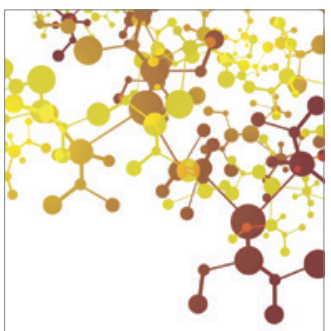

Journal of

Applied Chemistry

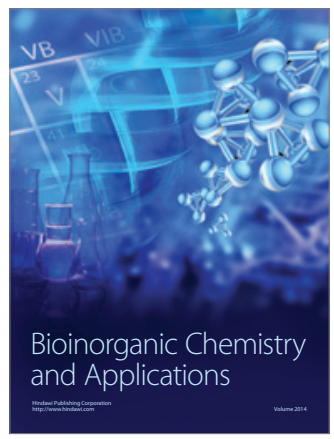

Inorganic Chemistry
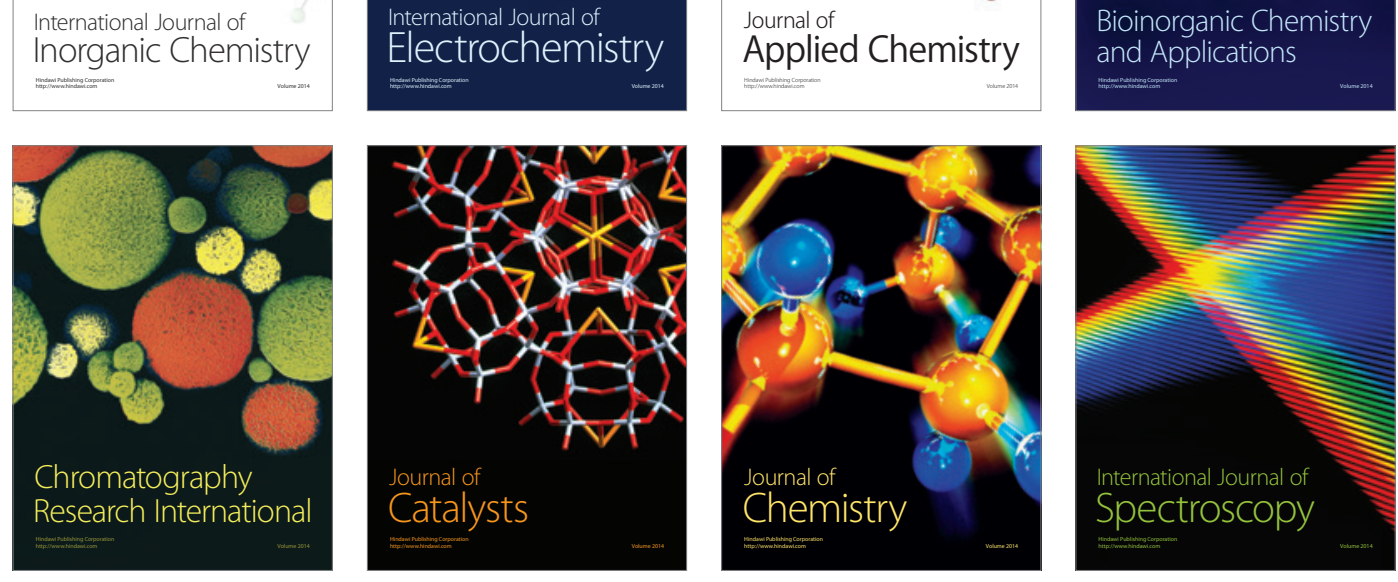